\title{
Pemilihan Strategi Penjualan Obat Apotik Antar Menggunakan Algoritma A Priori
}

\author{
Yahdi Kusnadi ${ }^{* 1)}$, Muhamad Auliya Ahsan²) \\ ${ }^{1)}$ Universitas Bina Sarana Informatika \\ 2) Sekolah Tinggi Manajemen Informatika dan Komputer Nusa Mandiri \\ ${ }^{*}$ Correspondence Author: yahdi.ydk@ bsi.ac.id, Jakarta, Indonesia \\ DOI: https://doi.org/10.37012/jtik.v6i2.213
}

\begin{abstract}
Abstrak
Para pesaing bisnis dituntut untuk memikirkan strategi penjualan untuk menarik perhatian pembeli. Sudah banyak cara yang digunakan oleh sebuah perusahaan untuk mendongkrak penjualan, bahkan cara yang serupa telah diikuti oleh perusahaan-perusahaan lain sebagai pesaing. Para pesaing bisnis khususnya Apotik Antar dituntut berpikir kreatif untuk meningkatkan penjualannya. Menggunakan database penjualan serta dibantu dengan algorithma A Priori data mining perusahaan akan mengetahui pola penjualan barang dan dapat menentukan pembelian stok barang dan penambahan stok secara tepat.
\end{abstract}

Kata Kunci : Strategi Promosi, Penjualan, A Priori

\begin{abstract}
Business competitors are required to think of a sales strategy to attract the attention of buyers. There are many ways used by a company to boost sales, even similar ways have been followed by other companies as competitors. Business competitors, especially Inter Pharmacies, are required to think creatively to increase sales. Using a sales database and assisted with algorithm A Priori data mining companies will know the pattern of selling goods and can determine the provision of goods and the right stock addition.
\end{abstract}

Keywords : Promotion Strategy, Sales, A Priori

\section{PENDAHULUAN}

Para pesaing bisnis dituntut untuk memikirkan strategi penjualan untuk menarik perhatian pembeli. Sudah banyak cara yang digunakan oleh sebuah perusahaan untuk mendongkrak penjualan, bahkan cara yang serupa telah diikuti oleh perusahaan-perusahaan lain sebagai pesaing. Apotik Antar adalah salah satu perusahaan yang terus melakukan upaya agar barang yang ia jual dapat semaksimal mungkin bersaing dengan perusahaan serupa.

Berdasarkan latar belakang di atas maka identifikasi permasalahan pada penelitian ini adalah bagaimana strategi penjualan obat yang tepat guna mendongkrak penjualan menggunakan metode A Priori. Permasalahan yang dibahas hanya data produk penjualan Minyak Angin selama 1 tahun. Ruang lingkup hanya membahas tentang analisa data penjualan produk minyak angin pada apotik antar guna menentukan promosi barang menggunakan algoritma apriori, dimana data didapat dari database penjualan obat apotik antar. 
Dalam penelitian ini memiliki perumusan hipotesis sebagai berikut :

H1 : Adanya pola hubungan pembelian barang menggunakan metode algoritma A Priori.

$\mathrm{H} 2$ : Adanya pengaruh signifikan antara penjualan obat apotik antar menggunakan analisa algoritma A Priori.

H3: Dapat ditentukan nilai confidence untuk mengetahui tingkat presentase pembelian terhadap barang menggunakan algorithma A Priori.

\section{METODE}

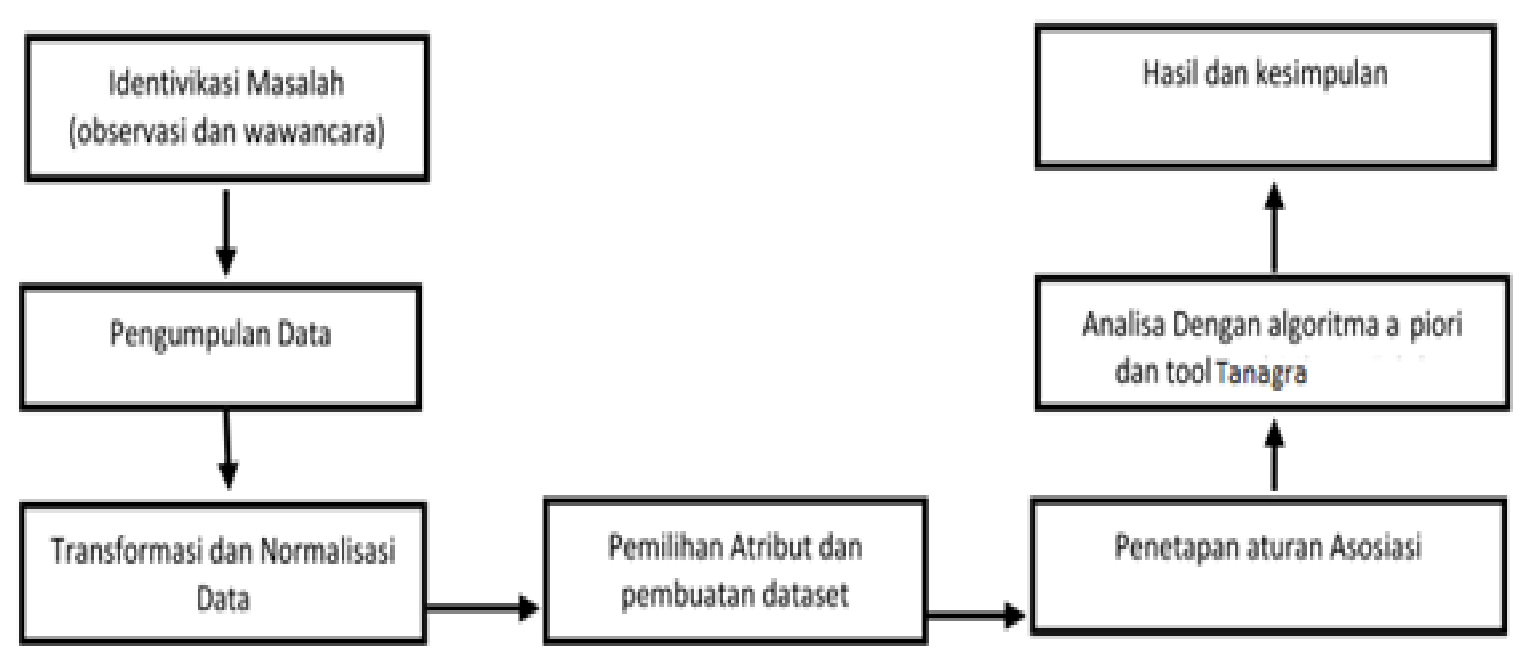

Gambar 1. Tahapan Penelitian

Dalam tahapan penelitian seperti pada gambar 1 diatas, penelitian ini dimulai dengan melakukan identifikasi masalah berupa observasi dan wawancara terhadap perusahaan Apotik Antar yang diteliti. Setelah itu dilakukan pengumpulan data penjualan pada sistem penjualan Apotik Antar yang akan dianalisa. Data yang telah terkumpul akan ditransformasi dan normalisasi agar tidak terjadi redudansi data. Lalu akan dilakukan pemilihan atribut dan pembuatan dataset. Setelah itu aturan A Priori akan ditetapkan serta akan dibantu menggunakan tool Tanagra untuk dianalisa sehingga mendapatakan hasil pengujian dan kesimpulan.

Data penjualan selama ini tidak tersusun dengan baik, sehingga data penjualan selama ini tidak dimanfaatkan dengan baik oleh perusahaan. Data tersebut hanya disimpan sebagai arsip atau pembukuan perusahaan dan tidak diketahui apa manfaat dari data-data yang ada tersebut. 
Tabel 1. Daftar Tipe Minyak Angin

\begin{tabular}{|c|l|}
\hline No & \multicolumn{1}{|c|}{ TIPE PRODUK MINYAK ANGIN } \\
\hline 1 & CAP LANG MINYAK KAYU PUTIH 15 ML \\
\hline 2 & CAPLANG MINYAK KAYU PUTIH 30 ML \\
\hline 3 & $\begin{array}{l}\text { FRESHCARE ROLL ON MINYAK ANGIN } \\
\text { STRONG (HOT) 10 ML }\end{array}$ \\
\hline 4 & MY BABY MINYAK TELON PLUS 150 ML \\
\hline 5 & MY BABY MINYAK TELON PLUS 60 ML \\
\hline 6 & MY BABY MINYAK TELON PLUS 90 ML \\
\hline 7 & CAP LANG MINYAK KAYU PUTIH 120 ML \\
\hline 8 & CAP LANG MINYAK KAYU PUTIH 15 ML \\
\hline 9 & CAP LANG MINYAK KAYU PUTIH 210 ML \\
\hline 10 & CAP LANG MINYAK KAYU PUTIH 60 ML \\
\hline 11 & KONICARE MINYAK TELON 125 ML \\
\hline 12 & KONICARE MINYAK TELON 30 ML \\
\hline 13 & KONICARE MINYAK TELON 60 ML \\
\hline 14 & KONICARE MINYAK TELON PLUS 125 ML \\
\hline 15 & KONICARE MINYAK TELON PLUS 60 ML \\
\hline
\end{tabular}

Data penjualan yang diteliti merupakan data penjualan produk Minyak Angin pada Apotik Antar selama 1 tahun, dimulai pada Januari 2019 sampai Desember 20219 Berikut ini merupakan data penjualan tahun 2019 :

Tabel 2. Data Penjualan Minyak Angin pada bulan Januari 2019

\begin{tabular}{|r|l|r|}
\hline \multirow{2}{*}{ No } & \multicolumn{1}{|c|}{ Produk Minyak Angin } & \multirow{2}{*}{ Total } \\
\cline { 2 - 3 } & \multicolumn{1}{|c}{ Januari 2019 } & \\
\hline 1 & CAP LANG MINYAK KAYU PUTIH 15 ML & 40 \\
\hline 2 & CAPLANG MINYAK KAYU PUTIH 30 ML & $\mathbf{9 0}$ \\
\hline 3 & $\begin{array}{l}\text { FRESHCARE ROLL ON MINYAK ANGIN } \\
\text { STRONG (HOT) 10 ML }\end{array}$ & 20 \\
\hline 4 & MY BABY MINYAK TELON PLUS 150 ML & 15 \\
\hline 5 & MY BABY MINYAK TELON PLUS 60 ML & 70 \\
\hline 6 & MY BABY MINYAK TELON PLUS 90 ML & 60 \\
\hline 7 & CAP LANG MINYAK KAYU PUTIH 120 ML & 15 \\
\hline 8 & CAP LANG MINYAK KAYU PUTIH 15 ML & 20 \\
\hline 9 & CAP LANG MINYAK KAYU PUTIH 210 ML & 7 \\
\hline 10 & CAP LANG MINYAK KAYU PUTIH 60 ML & $\mathbf{8 5}$ \\
\hline 11 & KONICARE MINYAK TELON 125 ML & 45 \\
\hline 12 & KONICARE MINYAK TELON 30 ML & $\mathbf{9 5}$ \\
\hline 13 & KONICARE MINYAK TELON 60 ML & 80 \\
\hline 14 & KONICARE MINYAK TELON PLUS 125 ML & 45 \\
\hline 15 & KONICARE MINYAK TELON PLUS 60 ML & 70 \\
\hline & & \\
\hline
\end{tabular}

Dari hasil penjualan Minyak Angin pada bulan Januari 2019 KONICARE MINYAK TELON 30 ML 95 item produk yang paling banyak terjual dan mendapatkan peringkat pertama paling tinggi. Disusul CAPLANG MINYAK KAYU PUTIH 30 ML dengan 90 item. Posisi terakhir yang paling banyak dijual yaitu CAP LANG MINYAK KAYU PUTIH 60 ML dengan 85 item. 
Tabel 3. Data Penjualan Minyak Angin pada bulan Februari 2019

\begin{tabular}{|c|c|c|}
\hline \multirow{2}{*}{ No } & Produk Minyak Angin & \multirow{2}{*}{ Tota } \\
\hline & Februari 2019 & \\
\hline 1 & CAP LANG MINYAK KAYU PUTIH 15 ML & 20 \\
\hline 2 & CAPLANG MINYAK KAYU PUTIH 30 ML & 30 \\
\hline 3 & $\begin{array}{l}\text { FRESHCARE ROLL ON MINYAK ANGIN } \\
\text { STRONG (HOT) } 10 \mathrm{ML}\end{array}$ & 42 \\
\hline 4 & MY BABY MINYAK TELON PLUS 150 ML & 6 \\
\hline 5 & MY BABY MINYAK TELON PLUS 60 ML & 45 \\
\hline 6 & MY BABY MINYAK TELON PLUS 90 ML & 60 \\
\hline 7 & CAP LANG MINYAK KAYU PUTIH 120 ML & 5 \\
\hline 8 & CAP LANG MINYAK KAYU PUTIH 15 ML & 20 \\
\hline 9 & CAP LANG MINYAK KAYU PUTIH 210 ML & 9 \\
\hline 10 & CAP LANG MINYAK KAYU PUTIH 60 ML & 70 \\
\hline 11 & KONICARE MINYAK TELON 125 ML & 30 \\
\hline 12 & KONICARE MINYAK TELON 30 ML & 65 \\
\hline 13 & KONICARE MINYAK TELON 60 ML & 70 \\
\hline 14 & KONICARE MINYAK TELON PLUS 125 ML & 45 \\
\hline 15 & KONICARE MINYAK TELON PLUS $60 \mathrm{ML}$ & 75 \\
\hline
\end{tabular}

Penjualan Minyak Angin pada bulan Februari 2019 KONICARE MINYAK TELON PLUS 60 ML 75 item produk yang paling banyak terjual dan mendapatkan peringkat pertama paling tinggi. Disusul KONICARE MINYAK TELON 60 ML dan CAP LANG MINYAK KAYU PUTIH 60 ML dengan masing - masing 70 item.

Tabel 4. Data Penjualan Minyak Angin pada bulan Desember 2019

\begin{tabular}{|r|l|r|}
\hline \multirow{2}{*}{ No } & \multicolumn{1}{|c|}{ Produk Minyak Angin } & \multirow{2}{*}{ Total } \\
\cline { 2 - 3 } & \multicolumn{1}{|c}{ Desember 2019 } & 79 \\
\hline 1 & CAP LANG MINYAK KAYU PUTIH 15 ML & $\mathbf{1 6 7}$ \\
\hline 2 & CAPLANG MINYAK KAYU PUTIH 30 ML & FRESHCARE ROLL ON MINYAK ANGIN \\
\hline 3 & STRONG (HOT) 10 ML & $\mathbf{1 5 6}$ \\
\hline 4 & MY BABY MINYAK TELON PLUS 150 ML & $\mathbf{1 2 4}$ \\
\hline 5 & MY BABY MINYAK TELON PLUS 60 ML & 31 \\
\hline 6 & MY BABY MINYAK TELON PLUS 90 ML & 93 \\
\hline 7 & CAP LANG MINYAK KAYU PUTIH 120 ML & 118 \\
\hline 8 & CAP LANG MINYAK KAYU PUTIH 15 ML & 34 \\
\hline 9 & CAP LANG MINYAK KAYU PUTIH 210 ML & 90 \\
\hline 10 & CAP LANG MINYAK KAYU PUTIH 60 ML & 65 \\
\hline 11 & KONICARE MINYAK TELON 125 ML & 34 \\
\hline 12 & KONICARE MINYAK TELON 30 ML & 79 \\
\hline 13 & KONICARE MINYAK TELON 60 ML & 53 \\
\hline 14 & KONICARE MINYAK TELON PLUS 125 ML & 115 \\
\hline 15 & KONICARE MINYAK TELON PLUS 60 ML & 34 \\
\hline
\end{tabular}

Penjualan Minyak Angin pada bulan Desember 2019 CAPLANG MINYAK KAYU PUTIH 30 ML dengan total penjualan 167 adalah produk yang paling banyak terjual dan mendapatkan peringkat pertama paling tinggi. Disusul FRESHCARE ROLL ON MINYAK ANGIN STRONG (HOT) 10 ML terjual 156. Posisi terakhir yang paling banyak dijual yaitu MY BABY MINYAK TELON PLUS 150 ML dengan 124 item. 


\section{HASIL DAN PEMBAHASAN}

Berdasarkan data penjualan minyak angin Apotik Antar selama 1 tahun didapatkan pola transaksi dengan menganalisis 3 tipe minyak angin yang paling banyak terjadi setiap bulannya. Untuk mempermudah didalam pembuatan tabulasi maka dibuat master data dengan cara menghilangkan duplikasi data dan membuat kode dari barang.

Tabel 5. Tabel Master Data dan Pengkodean

\begin{tabular}{|r|l|l|}
\hline \multicolumn{1}{|l|}{ NO. } & Item & Kode \\
\hline 1 & CAP LANG MINYAK KAYU PUTIH 120 ML & A001 \\
\hline 2 & CAP LANG MINYAK KAYU PUTIH 15 ML & A002 \\
\hline 3 & CAP LANG MINYAK KAYU PUTIH 210 ML & A003 \\
\hline 4 & CAP LANG MINYAK KAYU PUTIH 60 & A004 \\
\hline 5 & CAP LANG MINYAK KAYU PUTIH 60 ML & A005 \\
\hline 6 & CAPLANG MINYAK KAYU PUTIH 30 ML & A006 \\
\hline 7 & $\begin{array}{l}\text { FRESHCARE ROLL ON MINYAK ANGIN } \\
\text { BRONG (HOT) 10 ML }\end{array}$ & B001 \\
\hline 8 & KONICARE MINYAK TELON 125 ML & C001 \\
\hline 10 & KONICARE MINYAK TELON 30 ML & C003 \\
\hline 11 & KONICARE MINYAK TELON PLUS 125 ML & C004 \\
\hline 12 & KONICARE MINYAK TELON PLUS 60 ML & C005 \\
\hline 13 & MY BABY MINYAK TELON PLUS 150 ML & D001 \\
\hline 14 & MY BABY MINYAK TELON PLUS 90 ML & D002 \\
\hline
\end{tabular}

Tabel 6. Format Tabular

\begin{tabular}{|c|c|c|c|c|c|c|c|c|c|c|c|c|c|c|}
\hline \multirow[b]{2}{*}{$\begin{array}{c}\text { Transaksi Bulan } \\
\text { Ke - }\end{array}$} & \multicolumn{14}{|c|}{ Item } \\
\hline & $\begin{array}{l}\text { A00 } \\
1\end{array}$ & $\begin{array}{l}\text { A00 } \\
2\end{array}$ & $\begin{array}{l}\text { A00 } \\
3\end{array}$ & $\begin{array}{l}\text { A00 } \\
4\end{array}$ & $\begin{array}{l}\text { A00 } \\
5\end{array}$ & $\begin{array}{l}\text { A00 } \\
6\end{array}$ & $\begin{array}{l}\text { B00 } \\
1\end{array}$ & $\begin{array}{l}\text { C00 } \\
1\end{array}$ & $\begin{array}{l}\text { C00 } \\
2\end{array}$ & $\begin{array}{l}\text { C00 } \\
3\end{array}$ & $\begin{array}{l}\text { C00 } \\
4\end{array}$ & $\begin{array}{l}\mathrm{C} 00 \\
5\end{array}$ & $\begin{array}{l}\text { D00 } \\
1\end{array}$ & $\begin{array}{l}\text { D00 } \\
2\end{array}$ \\
\hline 1 & 0 & 0 & 0 & 0 & 1 & 1 & 0 & 0 & 1 & 0 & 0 & 0 & 0 & 0 \\
\hline 2 & 0 & 0 & 0 & 1 & 0 & 0 & 0 & 0 & 0 & 1 & 0 & 1 & 0 & 0 \\
\hline 3 & 0 & 1 & 0 & 0 & 0 & 0 & 0 & 0 & 1 & 1 & 0 & 0 & 0 & 0 \\
\hline 4 & 0 & 0 & 0 & 0 & 0 & 1 & 0 & 0 & 0 & 0 & 1 & 0 & 0 & 1 \\
\hline 5 & 1 & 0 & 0 & 0 & 0 & 0 & 0 & 0 & 1 & 0 & 1 & 0 & 0 & 0 \\
\hline 6 & 0 & 0 & 0 & 0 & 0 & 0 & 1 & 0 & 1 & 0 & 0 & 1 & 0 & 0 \\
\hline 7 & 0 & 0 & 0 & 0 & 0 & 0 & 0 & 1 & 1 & 1 & 0 & 0 & 0 & 0 \\
\hline 8 & 0 & 1 & 1 & 0 & 0 & 0 & 0 & 0 & 0 & 1 & 0 & 0 & 0 & 0 \\
\hline 9 & 1 & 0 & 0 & 0 & 0 & 0 & 0 & 0 & 1 & 0 & 0 & 0 & 0 & 1 \\
\hline 10 & 1 & 1 & 0 & 0 & 0 & 0 & 0 & 1 & 0 & 0 & 0 & 0 & 0 & 0 \\
\hline 11 & 0 & 1 & 0 & 0 & 0 & 0 & 1 & 1 & 0 & 0 & 0 & 0 & 0 & 0 \\
\hline 12 & 0 & 0 & 0 & 0 & 0 & 1 & 1 & 0 & 0 & 0 & 0 & 0 & 1 & 0 \\
\hline
\end{tabular}

Proses pembentukan $\mathrm{C} 1$ atau disebut dengan 1 itemset dengan jumlah minimum support = $16 \%$. Besar minimum support ini didukung penelitian terdahulu oleh Tampubolon et al. (2013:103) dengan menetapkan support minimal sama dengan 16\% persen.

Dengan rumus sebagai berikut :

$$
\operatorname{Support}(A)=\quad \frac{\Sigma \text { Transaksi yang mengandung A }}{\Sigma \text { Transaksi }} * 100 \%
$$

Minimal Support yang ditentukan adalah $16 \%$, jadi pada iterasi 1 yang tidak memenuhi minimal Support akan dihilangkan, terlihat seperti Tabel 7 dibawah ini: 
Tabel 7. Minimal Support 1 itemset 16\%

\begin{tabular}{|l|r|r|}
\hline Itemset & Jumlah & \multicolumn{1}{|l|}{ Support } \\
\hline A001 & 3 & $\mathbf{2 5 \%}$ \\
\hline A002 & 4 & $\mathbf{3 3 \%}$ \\
\hline A006 & 3 & $\mathbf{2 5 \%}$ \\
\hline B001 & 3 & $\mathbf{2 5 \%}$ \\
\hline C001 & 3 & $\mathbf{2 5 \%}$ \\
\hline C002 & 6 & $\mathbf{5 0 \%}$ \\
\hline C003 & 4 & $\mathbf{3 3 \%}$ \\
\hline C004 & 2 & $\mathbf{1 7 \%}$ \\
\hline C005 & 2 & $\mathbf{1 7 \%}$ \\
\hline D002 & 2 & $\mathbf{1 7 \%}$ \\
\hline
\end{tabular}

Proses pembentukan $\mathrm{C} 2$ atau disebut dengan 2 itemset dengan jumlah minimum support $=$ 16\%. Dapat diselesaikan dengan rumus sebagai berikut :

$$
\begin{aligned}
& \begin{array}{l}
\text { Support }(A, B)=P(A \cap B) \\
\text { Support }(A, B) \quad= \\
\sum \text { Transaksi yang mengandung A,B }
\end{array} * 100 \%
\end{aligned}
$$

Minimal Support yang ditentukan adalah 16\%, jadi kombinasi 2 itemset yang tidak memenuhi minimal Support akan dihilangkan, terlihat seperti Tabel 8 dibawah ini :

Tabel 8. Minimal Support 2 itemset 16\%

\begin{tabular}{|r|c|c|}
\hline Itemset & Jumlah & Support \\
\hline $\mathrm{A} 001, \mathrm{C} 002$ & 2 & $17 \%$ \\
\hline $\mathrm{A} 002, \mathrm{C} 001$ & 2 & $17 \%$ \\
\hline $\mathrm{A} 002, \mathrm{C} 003$ & 2 & $17 \%$ \\
\hline $\mathrm{C} 002, \mathrm{C} 003$ & 2 & $17 \%$ \\
\hline
\end{tabular}

Setelah semua pola frekuensi tinggi ditemukan, baru dicari aturan asosiasi yang memenuhi syarat minimum Confidence dengan menghitung Confidence aturan asosiatif $\mathrm{A} \rightarrow \mathrm{B}$.

Minimal Confidence ditetapkan $=60 \%$ dimana besar minimal confidence ini didukung penelitian terdahulu oleh Pane (2013:28) dengan menggunakan minimal confidence sebesar $60 \%$.

Nilai Confidence dari aturan $\mathrm{A} \rightarrow \mathrm{B}$ diperoleh dengan rumus sebagai berikut :

Confidence $=P(A / B)=$ $\Sigma$ Transaksi yang mengandung A dan B $\Sigma$ Transaksi A $* 100 \%$

Dari kombinasi 2 itemset yang telah ditemukan, dapat dilihat besarnya nilai support, dan confidence dari calon aturan asosiasi seperti tampak pada Tabel 9 dibawah ini: 
Tabel 9. Calon Aturan Asosiasi

\begin{tabular}{|l|r|r|}
\hline \multicolumn{1}{|c|}{ Aturan } & \multicolumn{2}{|c|}{ Confidence } \\
\hline $\begin{array}{l}\text { Jika membeli CAP LANG MINYAK KAYU PUTIH 120 ML (A001), maka akan membeli } \\
\text { KONICARE MINYAK TELON 30 ML (C002) }\end{array}$ & $2 / 3$ & $66,67 \%$ \\
\hline $\begin{array}{l}\text { Jika membeli KONICARE MINYAK TELON 125 ML (C001), maka akan membeli CAP LANG } \\
\text { MINYAK KAYU PUTIH 15 ML (A002) }\end{array}$ & $2 / 3$ & $66,67 \%$ \\
\hline $\begin{array}{l}\text { Jika membeli CAP LANG MINYAK KAYU PUTIH 15 ML (A002), maka akan membeli KONICARE } \\
\text { MINYAK TELON 60 ML (C003) }\end{array}$ & $2 / 4$ & $50 \%$ \\
\hline $\begin{array}{l}\text { Jika membeli KONICARE MINYAK TELON 60 ML (C003), maka akan membeli KONICARE } \\
\text { MINYAK TELON 30 ML (C02) }\end{array}$ & $2 / 4$ & $50 \%$ \\
\hline
\end{tabular}

Berdasarkan dari calon aturan asosiasi pada Tabel 9, maka yang memenuhi minimal support $16 \%$ dan minimal confidence $60 \%$ dapat dilihat pada Tabel 10 dibawah ini:

Tabel 10. Aturan Asosiasi Final

\begin{tabular}{|c|c|c|}
\hline Aturan & Support & Confidence \\
\hline $\begin{array}{l}\text { Jika membeli CAP LANG MINYAK KAYU PUTIH } 120 \text { ML (A001), maka akan } \\
\text { membeli KONICARE MINYAK TELON } 30 \text { ML (C002) }\end{array}$ & $17 \%$ & $66,67 \%$ \\
\hline $\begin{array}{l}\text { Jika membeli KONICARE MINYAK TELON } 125 \text { ML (C001), maka akan membeli } \\
\text { CAP LANG MINYAK KAYU PUTIH } 15 \text { ML (A002) }\end{array}$ & $17 \%$ & $66,67 \%$ \\
\hline
\end{tabular}

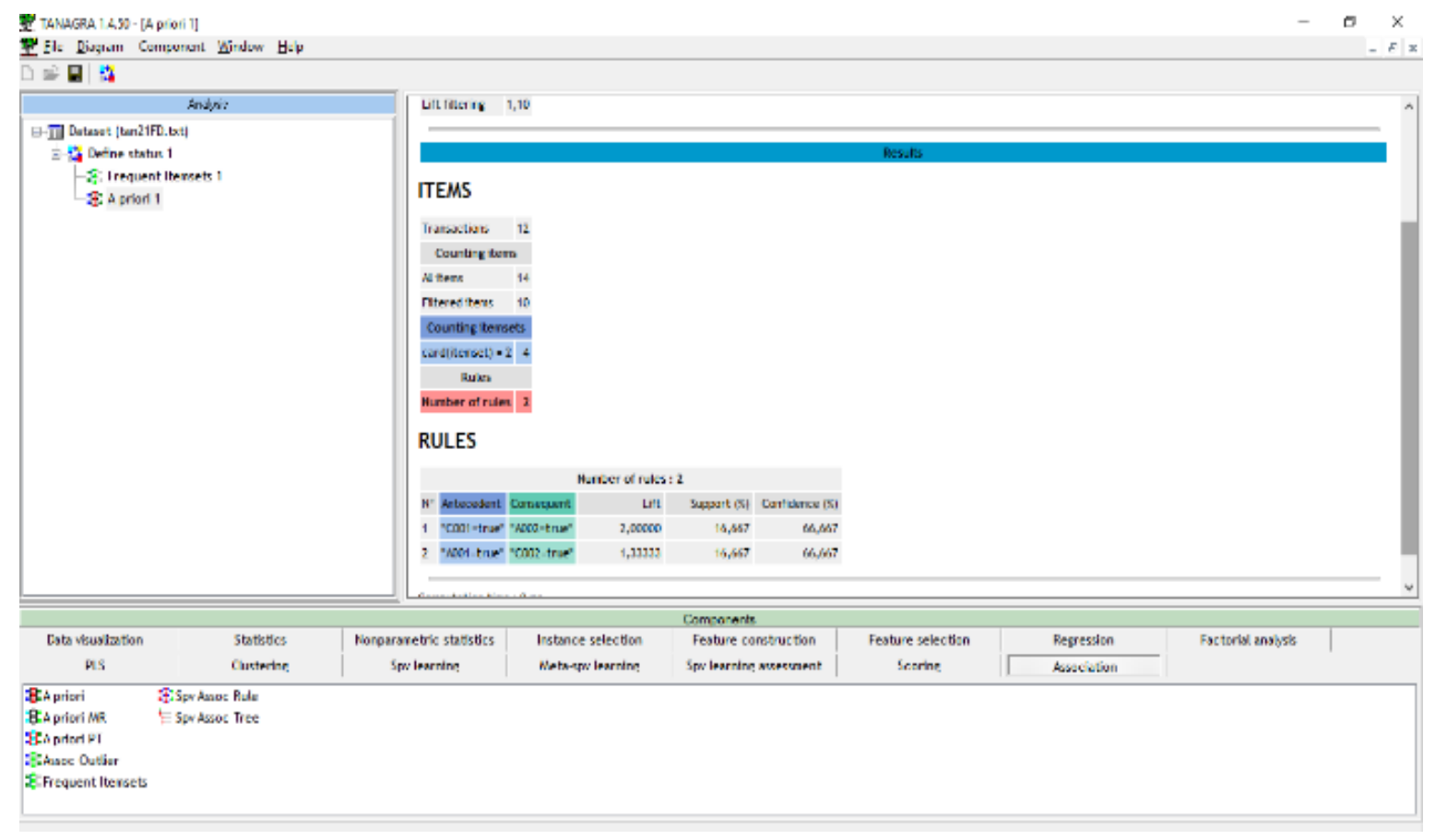

Gambar 2. Proses Asosiasi Final

Gambar diatas merupakan hasil output dari data mining pada penjualan Minyak Angin, maka dapat dibuat aturan (rule) seperti berikut dari output diatas:

\section{A001 (CAP LANG MINYAK KAYU PUTIH 120 ML), C002 (KONICARE MINYAK}

TELON 30 ML) dengan nilai Support 16,667\% dan nilai Confidence 66,667\%.

Berdasarkan pola aturan tersebut berarti " $66,667 \%$ dari transaksi di database yang 
memuat item A001 (CAP LANG MINYAK KAYU PUTIH 120 ML) juga memuat item C002 (KONICARE MINYAK TELON 30 ML), sedangkan 16,667\% dari seluruh transaksi yang ada di database memuat kedua item itu".

2. C001 (KONICARE MINYAK TELON 125 ML), A002 (CAP LANG MINYAK KAYU

PUTIH 15 ML) dengan nilai Support 16,667\% dan nilai Confidence 66,667\%.

Berdasarkan pola aturan tersebut berarti " $66,667 \%$ dari transaksi di database yang memuat item C001 (KONICARE MINYAK TELON 125 ML) juga memuat item A002 (CAP LANG MINYAK KAYU PUTIH 15 ML), sedangkan 16,667\% dari seluruh transaksi yang ada di database memuat kedua item itu".

\section{KESIMPULAN DAN REKOMENDASI}

Berdasarkan hasil pengumpulan dan analisis data dalam penelitian ini, maka dapat diambil kesimpulan bahwa:

Data Mining dapat di implementasikan dengan terhadap database penjualan dan dapat menemukan kecenderungan pola kombinasi itemsets sehingga dapat dijadikan sebagai informasi yang sangat berharga dalam pengambilan keputusan untuk mempersiapkan stok jenis barang apa yang diperlukan kemudian.

Pemanfaatan data mining untuk analisis asosiasi data transaksi dapat membantu manajemen perusahaan perdagangan untuk menentukan pola keterkaitan kemunculan barang dalam transaksi penjualan, yang pada akhirnya dapat digunakan untuk menyusun strategi penjualan.

Hasil dari penelitian ini adalah jika membeli CAP LANG MINYAK KAYU PUTIH 120 ML (A001), maka akan membeli KONICARE MINYAK TELON 30 ML (C002) dengan nilai Support $17 \%$ dan nilai Confidence 66,67\%. Lalu jika membeli KONICARE MINYAK TELON 125 ML (C001), maka akan membeli CAP LANG MINYAK KAYU PUTIH 15 ML (A002) dengan nilai Support 17\% dan nilai Confidence 66,67\%.

Strategi penjualan yang cocok pada pembahasan ini adalah memberikan penambahan stok lebih terhadap kombinasi penjualan dengan nilai Support dan nilai Confidence tertinggi.

\section{REFERENSI}

Amrin. (2017). Data Mining Dengan Algoritma Apriori untuk Penentuan Aturan Asosiasi Pola Pembelian Pupuk. Paradigma, XIX, 74-79. Diambil dari :

https://ejournal.bsi.ac.id/ejurnal/index.php/paradigma/article/download/1836/1409. (13 April 2018)

Badrul, M. (2016). Algoritma Asosiasi Dengan Algoritma Apriori Untuk Analisa Data Penjualan. Jurnal Pilar Nusa Mandiri, (2), 121-129. Diambil dari : 
http://ejournal.nusamandiri.ac.id/ejurnal/index.php/pilar/article/download/169/145. (13 April 2018)

Budihartanti, C. (2013). PENERAPAN DATA MINING BERDASARKAN ASOSIASI MENGGUNAKAN Pendahuluan. Techno Nusa Mandiri, IX(1), 20-28. Diambil dari

http://ejournal.nusamandiri.ac.id/ejurnal/index.php/techno/article/viewFile/42/39. (13 April 2018)

Fathansyah. (2013). Basis Data. Bandung: Informatika.

Iqbal, M. (2017). Analisa Keranjang Belanja Konsumen Pada Data Penjualan Bulan Ramadhan Menggunakan Algoritma Apriori ( Studi Kasus: Distro Coffepark Clothes Pekanbaru ). SNTIKI (Seminar Nasional Teknologi Informasi Komunikasi Dan Industri), 18-19. Diambil dari: http://ejournal.uinsuska.ac.id/index.php/SNTIKI/article/viewFile/3202/2159. (13 April 2018)

Larose, Daniel T. 2005. Discovering Knowledge in Data: An Introduction to Data Mining. John Willey \& Sons, Inc

Marthasari, G. I. (2016). Analisis Data Pendidikan Tinggi Menggunakan Pendekatan Data Mining. Jurnal Simantec, 5(3), 165-172. Diambil dari: http://eprints.umm.ac.id/36342/3/Marthasari\%20\%20Data\%20mining\%20Association\%20Rule\%20Mining\%20Algoritma\%20aprior i\%20keaktifan\%20siswa.pdf. (13 April 2018).

Pane, D. K. (2013). Implementasi Data Mining Pada Penjualan Produk Elektronik Dengan Algoritma Apriori ( Studi Kasus: Kreditplus ). Pelita Informatika Budi Darma, valume: $\quad I, \quad 25-29 . \quad$ Diambil dari: http://ejurnal.stmikbudidarma.ac.id/index.php/pelita/article/view/288/298. (13 April2018).

Rodiyansyah, S. F. (2015). Algoritma Apriori untuk Analisis Keranjang Belanja pada Data Transaksi Penjualan. Infotech, 1(1), 36-39. Diambil dari: http://jurnal.unma.ac.id/index.php/infotech/article/view/42. (13 April2018)

Salamah, E. N., \& Ulinnnuha, N. (2016). Analisis Pola Pembelian Obat dan Alat Kesehatan di Klinik Ibu dan Anak Graha Amani dengan Menggunakan Algoritma Apriori. INFORM, (xx), 1-6. Diambil dari: http://ejournal.unitomo.ac.id/index.php/inform/article/download/401/251. (13 April 2018)

Ummi, K. (2015). Analisa Data Mining Dalam Penjualan Sparepart Mobil Dengan Menggunakan Metode Algoritma Apriori (Studi Kasus : Di Pt . Idk 1 Medan). Analisa Data Mining Dalam, 8(3), 155-164. Diambil dari: http://ejournal.unitomo.ac.id/index.php/inform/article/download/401/251. (13 April 2018)

Tampubolon, K., Saragih, H., Reza, B., Epicentrum, K., Asosiasi, A., \& Apriori, A. (2013). Implementasi Data Mining Algoritma Apriori Pada Sistem Persediaan AlatAlat Kesehatan. Informasi Dan Teknologi Ilmiah, 93-106. Diambil dari :http://vokasi.uho.ac.id/statistika/assets/download/15121204230717.\%20Jurnal\%20 Kenendy.pdf (14 April 2018) 

Penerbit Gava Media. 